\title{
Association between Aquatic Micropollutant Dissipation and River Sediment Bacterial Communities
}

\author{
Claudia Coll,* Raven Bier, Zhe Li, Silke Langenheder, Elena Gorokhova, and Anna Sobek
}

Cite This: Environ. Sci. Technol. 2020, 54, 14380-14392

Read Online

ABSTRACT: Assessment of micropollutant biodegradation is essential to determine the persistence of potentially hazardous chemicals in aquatic ecosystems. We studied the dissipation half-lives of 10 micropollutants in sediment-water incubations (based on the OECD 308 standard) with sediment from two European rivers sampled upstream and downstream of wastewater treatment plant (WWTP) discharge. Dissipation half-lives (DT50s) were highly variable between the tested compounds, ranging from 1.5 to 772 days. Sediment from one river sampled downstream from the WWTP showed the fastest dissipation of all micropollutants after sediment RNA normalization. By characterizing sediment bacteria using $16 \mathrm{~S}$ rRNA sequences, bacterial community composition of a sediment

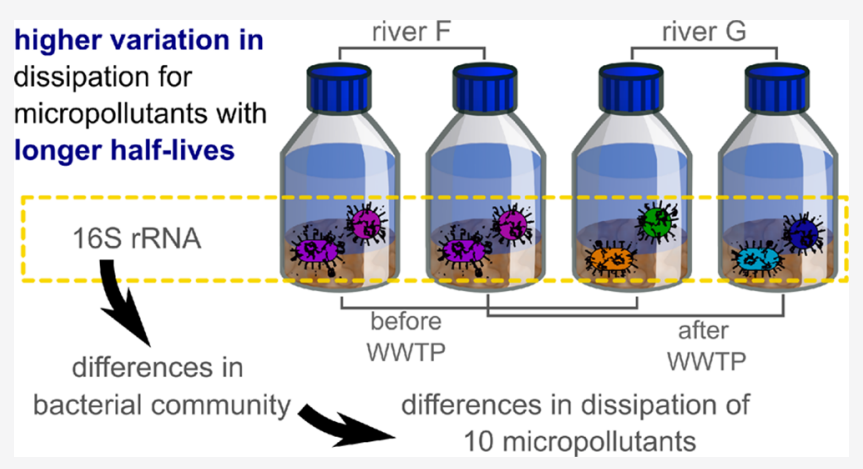
was associated with its capacity for dissipating micropollutants. Bacterial amplicon sequence variants of the genera Ralstonia, Pseudomonas, Hyphomicrobium, and Novosphingobium, which are known degraders of contaminants, were significantly more abundant in the sediment incubations where fast dissipation was observed. Our study illuminates the limitations of the OECD 308 standard to account for variation of dissipation rates of micropollutants due to differences in bacterial community composition. This limitation is problematic particularly for those compounds with DT50s close to regulatory persistence criteria. Thus, it is essential to consider bacterial community composition as a source of variability in regulatory biodegradation and persistence assessments.

\section{INTRODUCTION}

Persistent micropollutants degrade slowly and remain for a longer time in water, air, and/or soil, which makes them more likely to pose a risk to humans and the environment than nonpersistent chemicals. ${ }^{1}$ Biodegradation is an important pathway of removal for organic micropollutants in aquatic systems and could determine their environmental persistence. ${ }^{2,3}$ However, biodegradation is strongly affected by environmental conditions and at present cannot be predicted reliably using physical parameters to characterize the environmental matrix and compound physicochemical properties alone. ${ }^{4,5}$

OECD 308 is a standard method for testing aerobic and anaerobic transformation of chemicals in water-sediment systems. ${ }^{6}$ Dissipation half-lives (DT50s) obtained through OECD 308 can be compared with regulatory criteria, and therefore OECD 308 is frequently recommended in regulations as a tool to assess persistence (e.g., $\mathrm{REACH}^{7}$ ). Dissipation can be driven by biodegradation, abiotic degradation and/or sorption. These dissipation processes depend on the experimental conditions; ${ }^{8,9}$ thus, observed DT50s for a given chemical may vary substantially. ${ }^{10}$ For instance, biodegradation rates are affected by aerobic/anaerobic conditions. Further, the potential for biodegradation and sorption may be affected by the sediment organic carbon content and sediment-water ratio. ${ }^{10}$ Another parameter that may affect the outcome of the OECD 308 is the concentration of the chemical. Concentrations used in reported OECD 308 studies range from 40 to $50 \mu \mathrm{g} / \mathrm{L}^{8}, 50$ to $1000 \mu \mathrm{g} / \mathrm{L},{ }^{11}$ and 100 to $200 \mu \mathrm{g} / \mathrm{L} .^{12}$ Low micropollutant concentrations may result in longer DT50s, due to the compound in question being of limited bioavailability to its biodegraders. ${ }^{13,14}$ The effect of a high concentration on DT50s is dependent on the biodegrader community: its biomass, physiological stage (growth, maintenance or survival), adaptation potential as well as toxicity of the chemical. ${ }^{13-17}$

The term "biodegradation" covers a wide range of biologically mediated transformation pathways of a pollutant. The nature of these transformation processes, such as enzymatic reactions and membrane/surface interactions, are poorly known and vary among chemicals. ${ }^{18,19}$ Degradation pathways established for single species in the laboratory provide insight into relevant biodegradation pathways driven by microorganisms but may not represent the degradation pathways in the environment. In nature,

Received: July 4, 2020

Revised: September 14, 2020

Accepted: October 7, 2020

Published: October 26, 2020

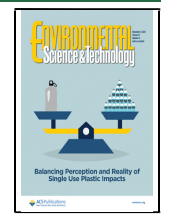


microbial consortia are more likely to perform biodegradation than pure cultures, through complementarity in functional traits. ${ }^{20,21}$ Therefore, it is relevant to study the degradation capacity of microorganisms at community levels rather than in individual taxa. ${ }^{22}$

Microbial communities in the environment include bacteria, eukaryota, and archaea, which may all contribute to the dissipation of micropollutants. ${ }^{23-25}$ Bacteria, however, dominate these communities in river sediments ${ }^{23-26}$ and possess a broad array of functional traits as a product of rapid evolution of enzymes and lateral gene transfer. ${ }^{20,27}$ It is therefore expected that bacteria possess enzymes capable of the complete or partial degradation of micropollutants. It has been proposed that degradation pathways provided by a few taxa ("rare" functions) are more likely to be present in communities with high taxonomic diversity because they are likely to have functional saturation and harbor taxa with the rare function. ${ }^{28,29}$ Bacterial taxonomic diversity has been correlated to the overall capacity for micropollutant degradation in wastewater treatment plants (WWTPs) ${ }^{28}$ and to the dissipation of 22 out of 31 micropollutants in a flume study; ${ }^{30,31}$ showing that community diversity serves as a predictor of the degrading capacity for the majority of chemicals. However, the degradation capacity of micropollutants can be uncoupled from taxonomic diversity when chemicals are degraded by a wide range of functionally redundant taxa or when taxonomic and functional diversity are not strongly associated. ${ }^{29}$ The OECD 308 does not require an assessment of the bacterial community, and thus the variability in dissipation capacity due to differences in bacterial community diversity and composition is neglected.

In this work, an experimental setup based on the OECD 308 standard was used to study the relationship between bacterial community composition and the dissipation rates (expressed as DT50s) of 10 common micropollutants. The collective degradation capacity of the community was assessed instead of the individual identities and degradation capacities of bacterial isolates involved in biotransformation of the micropollutants. The composition of bacterial communities can vary greatly between rivers, ${ }^{32}$ which could result in differences in the degradation capacity between them. Sediment from two rivers impacted by a municipal WWTP, previously studied by Li et al., ${ }^{33}$ were used to test the hypothesis that the previously observed significant differences in the dissipation of micropollutants between the river sediments ${ }^{33}$ are associated with differences in bacterial community composition in OECD 308 tests. Two sites were sampled in each river, up- and downstream from the discharge of a WWTP, to assess if the sampling location could lead to differences in dissipation of micropollutants. Two initial concentrations were used, including a high concentration of micropollutants to evaluate if highly concentrated micropollutants could lead to a reduced dissipation capacity in OECD 308 tests.

\section{MATERIALS AND METHODS}

Study Sites and Sampling. Sediment and water samples were collected from River Fyris in Sweden and River Gründlach in Germany. Each river was sampled upstream and downstream of the discharge point of a municipal WWTP (Figure 1A). The rivers were chosen because $\mathrm{Li}$ et al. ${ }^{33}$ found significant differences between their relative dissipation of 14 pharmaceuticals. Specific details of the sediment characteristics and sampling procedures are provided in Figure $1 \mathrm{~B}$ and the Supporting Information (SI, Tables S1-S3). The four sites sampled are referred to as Fyris upstream and Fyris downstream (F1 and F2), and Gründlach upstream and Gründlach downstream (G1 and G2). F2 and G2 are close to the sampling sites in the respective rivers studied by $\mathrm{Li}$ et al. ${ }^{33}$ The sampled sediments differed in total organic carbon content (TOC) and texture (SI Tables S1-S3)).

Compound Selection. Micropollutants addressed in this study are commonly found in wastewater, have a broad range of biodegradability and are expected to display a low sorption potential to organic carbon $\left(\log D_{\mathrm{OW}}<3\right.$, SI Table S4). The set of micropollutants included an artificial sweetener, acesulfame-K, caffeine, and eight pharmaceuticals: acetaminophen, caffeine, carbamazepine, diclofenac, furosemide, metformin, oxazepam, tramadol, and venlafaxine; see SI Table S4 for details.

Experimental Setup. Incubations following the OECD 308 standard were performed in $250 \mathrm{~mL}$ borosilicate glass bottles, each containing $60 \mathrm{~g}$ of wet sediment and $180 \mathrm{~mL}$ of synthetic river water (Figure 1C). Two test systems were set with different initial concentrations of the micropollutants: high $(\mathrm{H}$; nominal concentration of $2000 \mu \mathrm{g} / \mathrm{L})$ and low (L; $20 \mu \mathrm{g} / \mathrm{L})$. The low concentration of micropollutants was higher than the levels measured in water from both rivers (SI Table S4 and Li et al. ${ }^{33}$ ), but such concentrations have been observed in other rivers. ${ }^{34,35}$ Lower concentrations were avoided to ensure detection down to approximately $5 \%$ of the initial concentration of the micropollutant. For the high concentration, comparable in situ levels have only been reported in a study on an effluent from a WWTP in India serving bulk manufacturer companies. ${ }^{36}$ To compare the dissipation and biodegradation between sediment and natural water, a test system was setup with $200 \mathrm{~mL}$ of river water (W) and no sediment. Two types of control incubations were established to assess dissipation due to abiotic processes: sediment incubations (SC) with triple-sterilized sediment $\left(121{ }^{\circ} \mathrm{C}, 20 \mathrm{~min}\right)$ to account for abiotic sorptive processes and water incubations (WC) with triple-sterilized deionized water to account for abiotic nonsorptive processes (Figure 1C). A set of sediment incubations without chemicals served as an unamended control (UC).

The synthetic river water used in the sediment-water incubations (H, L, UC, and SC) was prepared from autoclaved deionized water amended with macro- and micronutrients (SI Table S4) as described elsewhere. ${ }^{12}$ After an acclimation period of 10 days, the water above the sediment surface was removed and replaced with a fresh synthetic river water containing a mixture of the 10 micropollutants. Triplicate incubations for each sediment (F1, F2, G1, and G2) were amended with the micropollutant mixture at the two test concentrations. The sediment controls (SC; $n=4)$ were amended with the mixture at the high concentration $(2000 \mu \mathrm{g} / \mathrm{L})$ only. For the river water $(\mathrm{W} ; n=12)$ and the water control incubations (WC; $n=3$ ), only $50 \mathrm{~mL}$ of surface water were removed and replaced with amended synthetic water for a final concentration of micropollutants of $2000 \mu \mathrm{g} / \mathrm{L}$. All incubations were kept at $16{ }^{\circ} \mathrm{C}$ for the duration of the test. The water phase was aerated daily with pressurized air until oxygen saturation. Oxygen and $\mathrm{pH}$ were monitored daily during the first week after spiking and at the end of the test (details in SI and Figure S1).

A sample of $1 \mathrm{~mL}$ of surface water was collected from each incubation ( $\mathrm{H}, \mathrm{L}, \mathrm{UC}, \mathrm{SC}, \mathrm{W}$, and WC) after addition of the micropollutant mixture (at $\sim 40 \mathrm{~min}$ and $4 \mathrm{~h}$ ) and after 1, 2, 4, $7,14,21,30$, and 40 days. These samples were stored at $-20{ }^{\circ} \mathrm{C}$ until further analysis. At the end of the test, $10 \mathrm{~g}$ of 
A.

River Fyris (F), Sweden

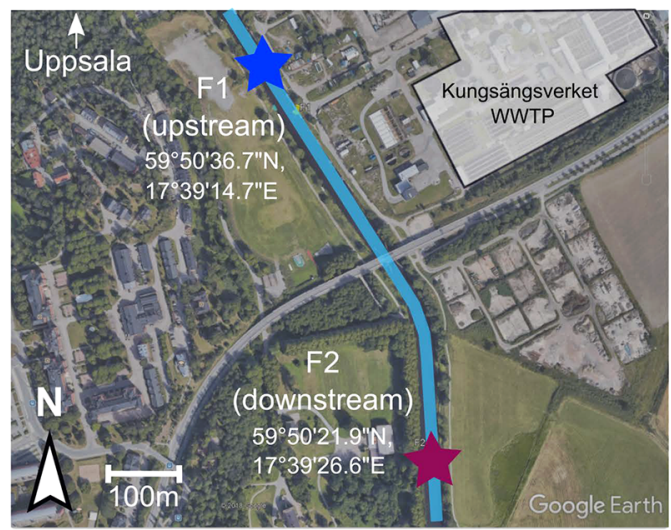

River Gründlach (G), Germany

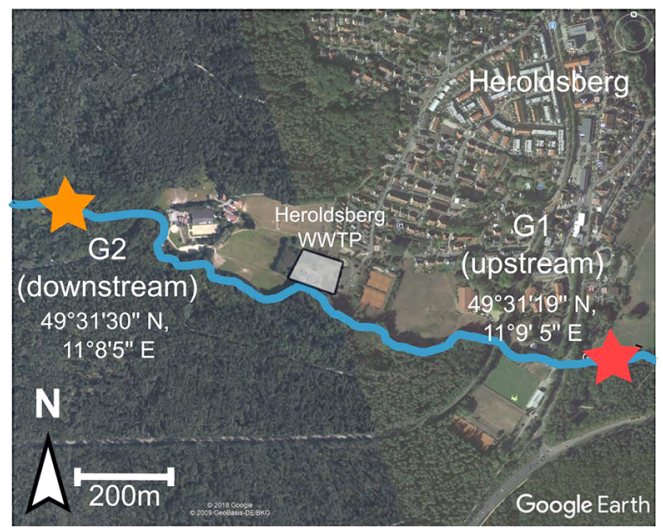

B.
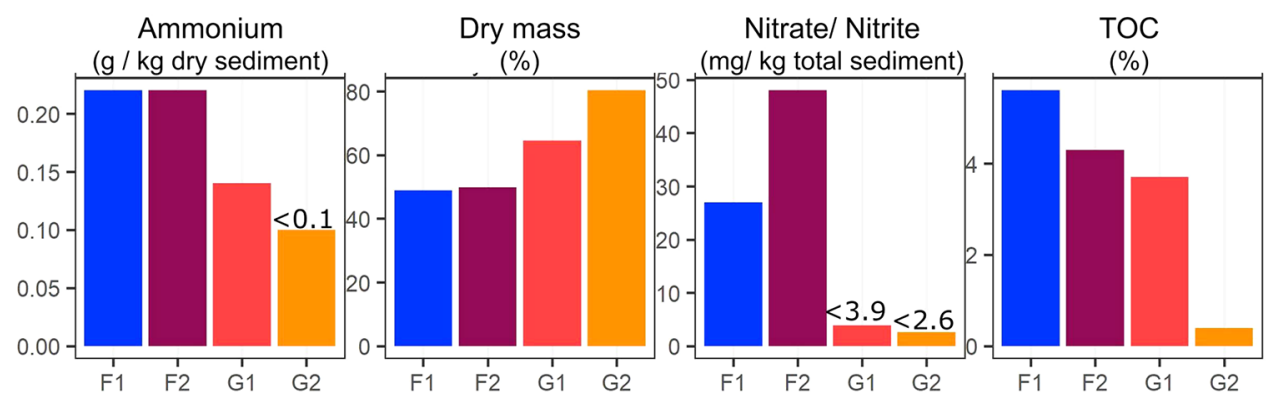

C.

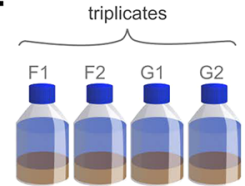

High concentration $(\mathrm{H})$ $2000 \mu \mathrm{g} / \mathrm{I}$

$60 \mathrm{~g}$ sediment

$180 \mathrm{ml}$ synthetic river water

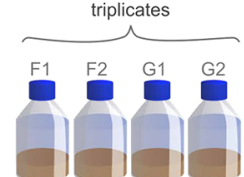

Low concentration $(\mathrm{L})$ $20 \mu \mathrm{g} / \mathrm{l}$ $60 \mathrm{~g}$ sediment $180 \mathrm{ml}$ synthetic river water

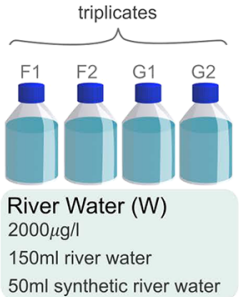

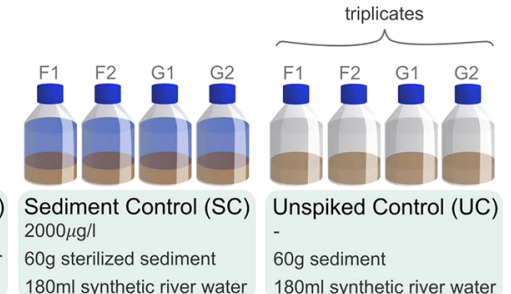

Figure 1. (A) Sampling sites in River Fyris (F) and River Gründlach (G) upstream (1) and downstream (2) of the discharge of the local WWTP (map data: Google 2018, GeoBasis-DE/BKG). (B) Ammonium concentration (g/kg dry sediment), dry mass (\% total sediment), nitrite/nitrate concentration $(\mathrm{mg} / \mathrm{kg}$ total sediment) and TOC concentration (\% total sediment). (C) Experimental setup with sediment-water incubations at high (H: $2000 \mu \mathrm{g} / \mathrm{L} ; 12$ incubations) and low (L: $20 \mu \mathrm{g} / \mathrm{L} ; 12$ incubations) initial micropollutant concentrations, river water (W; 12 incubations), water control (WC; 3 incubations), sediment control (SC; 4 incubations), and a control without added micropollutants (UC; 12 incubations).

sediment were collected from each treatment and stored at $-80{ }^{\circ} \mathrm{C}$ for bacteria community analysis.

16S rRNA and DNA Extraction and Sequencing. Using RNeasy PowerSoil Total RNA Kit (Qiagen), total RNA was extracted from the homogenized sediment samples $(2 \mathrm{~g})$ from treatments $\mathrm{H}, \mathrm{L}$, and SC. The resulting RNA concentration in each sample was assessed using a NanoDrop Spectrophotometer (NanoDrop 2000, Thermo Scientific). DNA contamination was removed by treating the extract with a DNase I (Invitrogen) treatment for $15 \mathrm{~min}$. Reverse transcription of the RNA was conducted using RevertAid $\mathrm{H}$ Minus First Strand cDNA Synthesis Kit (Thermo Fisher Scientific).

DNA and RNA were coextracted from water samples (treatments W and WC) using a modified protocol from EasyDNA kit (Invitrogen, Carlsbad, CA), ${ }^{44}$ but only DNA could be amplified in polymerase chain reaction (PCR). The sequencing data of sediment samples were therefore based on $16 \mathrm{~S}$ rRNA and hence represent active bacteria, whereas the water sequencing data were based on the 16S rRNA gene and include active and nonactive fractions of the bacterial community.

Samples of transcribed cDNA and DNA were amplified in $20 \mu \mathrm{L}$ duplicate reactions with PCR using the bacterial $16 \mathrm{~S}$ rRNA gene primers $341 \mathrm{~F}^{45}$ and $805 \mathrm{NR}^{46}$ and barcoded with dual index 2-step procedure (details in SI). After purification, pooled samples were submitted to SNP\&SEQ Technology platform at SciLife in Uppsala, Sweden for Illumina MiSeq PE300bp sequencing with a $10 \%$ PhiX phage sequencing library spike (details in SI). Approximately 21.4 million paired reads were received. The DADA2 ${ }^{37}$ pipeline in QIIME2 ${ }^{38}$ was used to analyze the $16 \mathrm{~S}$ rRNA gene amplicon sequences. Primers were removed first using cutadapt ${ }^{39}$ (v2.7 with Python 3.7.6), and sequences were trimmed to a minimum of $249 \mathrm{bp}$ and a maximum of $301 \mathrm{bp}$. Quality filtering was set to a maximum of two expected errors for all sequences. Sequences were then dereplicated and chimeric sequences were removed. Taxonomy was assigned to amplicon sequence variants (ASVs) 
using the 99\% ASV reference database SILVA $132 .^{40}$ After removing chloroplasts, Archaea, blank contamination ASVs and singletons, 34,767 bacterial ASVs remained (details in SI). The composition of the bacterial communities in the water samples is shown in the SI (Figure S5).

Micropollutant Analysis in Water. Information on chemicals and reagents is provided in the SI. Prior to analysis, $10 \mu \mathrm{L}$ of the internal standard solution containing $25 \mathrm{ng}$ of each isotope-labeled compound were added to each water sample. The sample was thereafter vortexed and filtered into a glass LC vial using a $0.45 \mu \mathrm{m}$ PTFE syringe filter. The samples from treatments at the high concentration level were diluted 20-fold with Milli-Q water before the internal standard solution was added. All samples were analyzed with ultrahigh-performance liquid chromatography (ACQUITY UHPLC system, Waters, Manchester, U.K.) coupled with a triple quadrupole mass spectrometer (Xevo TQS, Waters) based on the protocol by Li. et al. ${ }^{41}$ Separation was achieved using an HSS T3 column (100 mm $\times 2.1 \mathrm{~mm}$, particle diameter of $1.8 \mu \mathrm{m}$; Waters). More details on the analytical method and quality controls are provided in the SI.

The measured concentrations in all treatments $(\mathrm{H}, \mathrm{L}, \mathrm{W}$, WC, and SC) were fitted to pseudo-first order dissipation kinetics using the mkin package (version 0.9 .49 .5$)^{42}$ in the $\mathrm{R}$ software (version 3.6.1), ${ }^{43}$ to obtain the DT50s. The concentrations were fitted directly to an exponential function as neither outliers nor lag-phase were observed. Concentration decline over time was generally well represented by first order kinetics, with a few exceptions (SI Table S8). The DT50s were corrected for differences in biomass by normalizing $k_{\text {dis }}$ to RNA concentration according to eq $1:^{9,44}$

$$
\mathrm{DT} 0_{\text {norm }}=\mathrm{B}_{\mathrm{RNA}} \times \mathrm{DT} 50
$$

where DT50 ${ }_{\text {norm }}$ is the DT50 normalized to biomass (day.ng $\mathrm{RNA} / \mathrm{g}$ sediment) and $\mathrm{B}_{\mathrm{RNA}}$ is the RNA concentration in each sample (ng RNA/g sediment). Normalization to RNA concentration instead of TOC $^{9}$ was performed because it provides a better proxy of the metabolically active mass of living organisms, whereas TOC includes all organic matter present in the sediment. The RNA extracted from environmental samples includes RNA from archaea and microeukaryotes as well as from bacteria, and therefore, normalizing 16S rRNA sequences to total RNA may overestimate or underestimate the bacteria assemblage when comparing between samples.

Identification of Transformation Products. To confirm the occurrence of degradation in the test systems, a selection of samples (SI Table S6) was analyzed with UHPLC coupled to a Q Exactive HF Hybrid Quadrupole-Orbitrap MS (Thermo Fisher Scientific, San Jose, CA) to identify well-documented transformation products (TPs; carbamazepine: carbamazepine10,11-epoxide and 10,11-dihydro-10,11-dihydroxycarbamazepine; metformin: guanyl urea; tramadol: desmethyltramadol; and venlafaxine: o-desmethylvenlafaxine). Chromatographic separation was achieved using a reversed-phase Hypersil GOLD aQ C18 polar-end-capped column $(2.1 \mathrm{~mm} \times 100 \mathrm{~mm}$; particle size of $1.9 \mu \mathrm{m}$; Thermo Fisher Scientific) with a binary mobile phase gradient consisting of (A) water and (B) acetonitrile, both containing $0.1 \%$ formic acid. The nontarget screening workflow has been established ${ }^{45}$ with an achieved identification confidence level of I for all of the selected TPs except desmethyltramadol for which the identification confidence level II was achieved. ${ }^{46}$ Semiquantification was carried out for these compounds using their peak areas. Detailed information on the method is described in $\mathrm{Li}$ et al. ${ }^{45}$

Statistical Analysis. One-tailed $t$ tests were used to examine if the kinetic constant $(\mathrm{k})$ was different from zero. A rank-based multivariate nonparametric MANOVA ${ }^{47}$ (package rankMANOVA in the $\mathrm{R}$ software) was used to evaluate the effects of river ( $F$ vs $G$ ), location (upstream vs downstream), and initial concentration ( $\mathrm{H}$ vs $\mathrm{L}$ ) on the DT50s and DT50 norm for each of the test compounds. Tukey pairwise comparisons were performed to investigate differences for individual factors and compounds (function "pairwise"). ${ }^{47}$ Further details are in the SI.

Fisher's alpha diversity and Shannon diversity were calculated with the $\mathrm{R}$ phyloseq package (version 1.30 .0$)^{48}$ for each sample in the $\mathrm{H}$ and $\mathrm{L}$ incubations. The ASV counts were rarefied prior to calculation of Fisher's alpha, whereas Shannon diversity was calculated using nonrarefied data (details in SI). Then, differences in diversity between rivers, location and initial concentrations were evaluated with a three-way ANOVA for each index. The assumptions of normality and homogeneity of variance were inspected with Shapiro-Wilk and Levene tests, respectively (SI Tables S17 and S18).

Community composition was compared between the rivers and treatments using permutational multivariate analysis of variance (PERMANOVA, function "adonis" in R package vegan ${ }^{49}$ version 2.5-6) after confirming no violation of homogeneity of variances ${ }^{50}$ among groups using "betadisper" and "permutest" also in vegan with 999 permutations $(F=2.38, p=0.09)$. To assess further dissimilarities in community structure, a variance stabilizing transformation (VST) available in the DESeq2 package (version 1.26.0) $)^{51}$ was performed prior to evaluation of the pairwise dissimilarity between the treatments using Euclidean distance matrix followed by principal coordinate analysis (PCoA).

Differences in the ASV composition were related to the dissipation capacity of the sediment by comparing ASV abundance in the sediment samples with the lowest normalized DT50s of the test compounds (i.e., samples in which dissipation was "fast") to samples with long DT50s. The differential abundance of bacterial genera between samples with fast and slow dissipation was tested using the DESeq 2 package and nonrarefied ASV counts. ${ }^{52}$ Wald test and adjusted $p$-values were used to determine if each calculated $\log _{2}$ fold-change differed significantly from zero. For the purpose of this study, taxa with a $\log _{2}$ fold-change ratio $\geq|2|$ and Benjamini-Hochberg adjusted $p$-values $\leq 0.05$ were considered differentially abundant. The slow dissipation groups were used as reference, therefore a $\log _{2}$ fold-change $>0$ implies that the genus is more abundant in the fast dissipation group.

\section{RESULTS AND DISCUSSION}

Dissipation of Micropollutants in Bottle Incubations with Sediment and/or Water. Variation in DT50s of Micropollutants in Sediment-Water Incubations. The 10 micropollutants displayed DT50s that ranged from $<4 \mathrm{~d}$ for acetaminophen in all sediment-water incubations to $>200 \mathrm{~d}$ for carbamazepine and acesulfame-K (Table 1), thus covering a wide spectrum of dissipation rates. Large variations in DT50s were observed for individual compounds (Table 1), with higher relative standard deviations (RSD) of DT50s of compounds with slower dissipation (i.e., tramadol, acesulfame-K, and carbamazepine, Table 1 ). We hypothesize that similar to the findings in activated sludge of WWTPs, ${ }^{28}$ chemicals with low environmental half-lives are degraded through broadly 


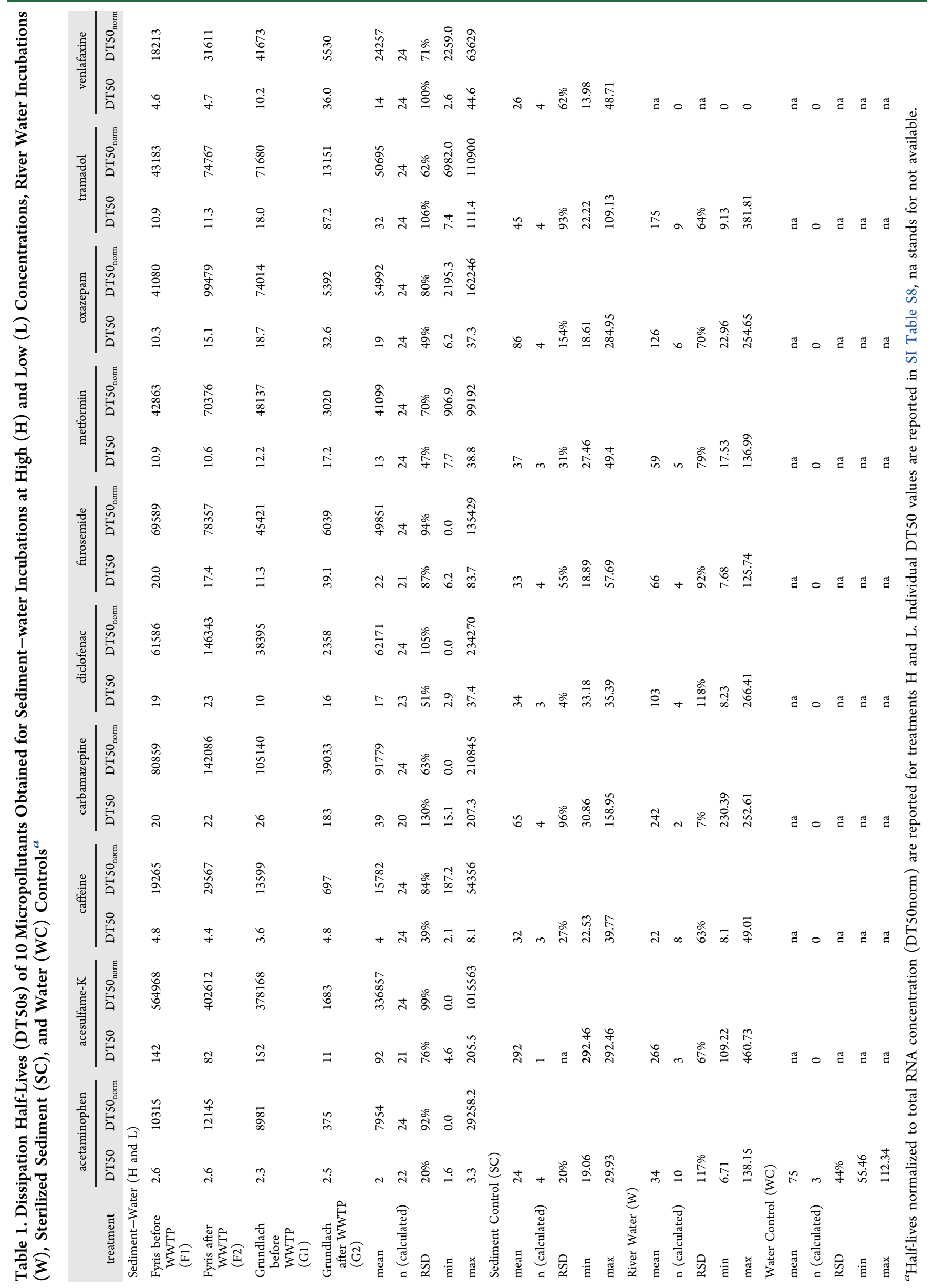


distributed functions carried out by many bacterial taxa present in a wide range of sediment communities. In contrast, the degradation capacity of more persistent chemicals can be more heterogeneous in the environment leading to higher variability in DT50s between sediments.

For all 10 micropollutants, significant differences in DT50s between the rivers and between test concentrations were found (rankMANOVA: $p<0.05$, SI Table S13). The river effect was significant for carbamazepine, diclofenac, metformin, oxazepam, tramadol, and venlafaxine $(p<0.05$, SI Table S15). In general, lower DT50 values were found at the low concentrations compared to the high concentrations; the difference was significant for acesulfame, caffeine, carbamazepine, diclofenac, and metformin. These results support our hypothesis that the concentration used in OECD 308 may affect the dissipation capacity of the sediment ${ }^{13,14}$ and thereby have a significant impact on the determined DT50s. Moreover, the location effect was significant for acesulfame- $\mathrm{K}$, carbamazepine and oxazepam $(p<0.05$, SI Table S15). Neither river nor location was consistently more efficient in dissipating all micropollutants.

Acesulfame-K Dissipates Faster in Incubations with Sediment Sampled Downstream of WWTPs. In total, 13 DT50s from incubations using river sediment F1 and G1 (both at high and low concentration) as well as with sediment F2 (only high concentration) (Table 1) exceeded the 120-day persistence criteria in sediment ${ }^{7}$ or showed no significant dissipation $\left(k_{\text {dis }} p\right.$-value $\left.\geq 0.05\right)$. Acesulfame- $\mathrm{K}$ was the most persistent micropollutant in our experimental setup, which agrees with earlier findings both in a previous dissipation study in Rivers Fyris and Gründlach ${ }^{33}$ and in a lake study. ${ }^{53}$ Adaptation and evolution of bacterial catabolic biodegradation of acesulfame-K in WWTPs was recently reported ${ }^{54,55}$ in agreement with findings that WWTP discharge can affect bacterial functions related to micropollutants in rivers and lakes, such as antibiotic resistance. ${ }^{56,57}$

The faster dissipation of acesulfame- $\mathrm{K}$ in sediment G2 after the WWTP also suggests that the pre-exposure to acesulfame-K through WWTP discharge has enhanced the bacterial capacity for its biodegradation in this particular river. This capacity for dissipation of acesulfame- $K$ potentially developed between the time of the study by $\mathrm{Li}$ et.al. ${ }^{33}$ (2014) and the present study (2016), in line with the timeline proposed by Kahl et al. ${ }^{54}$ for German Rivers Elbe and Mulde. However, the faster dissipation of acesulfame- $\mathrm{K}$ in sediment $\mathrm{F} 2$ compared to $\mathrm{F} 1$ was only observed at the low concentration, in support of our finding that the biodegradation capacity of (some) sediment bacterial communities can be reduced at exposure to high concentrations of micropollutants.

Degradation of Carbamazepine Supported by the Occurrence of Its Transformation Products. Carbamazepine had DT50s above the persistence criteria for sediment in all six incubations with sediment from G2, but DT50s were lower than the 120-days criteria in sediments F1, F2, and G1 (Table 1). Carbamazepine was found to dissipate slower than other compounds in river studies, ${ }^{33,58}$ laboratory experiments ${ }^{30,59-63}$ and lake studies. ${ }^{64,65}$ Faster dissipation of carbamazepine in sediment-water systems has been reported to be due to sorption to organic matter, ${ }^{6,66}$ in line with carbamazepine's comparably high $\log D_{\text {ow }}$ of 2.8 (SI Table S4). Carbamazepine (and furosemide) had DT50s from incubations with nonsterilized sediment $(\mathrm{H})$ and sterilized sediment controls (SC) that were in the same range ( $<30 \%$ difference) for most samples (Table 1 , SI Table S9), which could indicate an impact of sorption on the dissipation in nonsterilized treatments. Carbamazepine-10,11-epoxide, a common TP of carbamazepine, was found in nonsterilized incubations ( $\mathrm{H}$ and $\mathrm{L}$ ) and in the sterilized control (SC), whereas substantially lower concentrations were found in the control without added micropollutants (UC) for all sediment types (Figure 2). The TP 10,11-dihydro-10,11-dihydrocarbamazepine was not consistently found. The occurrence of carbamazepine-10,11-epoxide supports that carbamazepine was degraded in $\mathrm{H}$ and $\mathrm{L}$ treatments and in the sterilized control, and thus that the control was not sterile throughout the incubation. Bacterial ASVs in the sterilized controls which could support the degradation of carbamazepine are described in SI Section S9.

Dissipation of Tramadol, Venlafaxine, and Their Transformation Products. The DT50s of oxazepam, tramadol, and venlafaxine presented a similar pattern and were positively correlated with each other (Pearson's $r>0.70$ ). These three compounds had faster dissipation in incubations with sediment from F1 and slower in sediment from G2 (Table 1). Similar results were previously observed in situ for tramadol dissipation in the same rivers. ${ }^{33}$ Data on dissipation reported in the literature for oxazepam (DT50s: 54 to $\sim 240$ days), ${ }^{62,67,68}$ tramadol

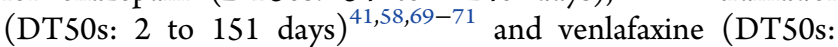
5 to 137 days $)^{58,69,71,72}$ vary widely, which further suggests that bacterial communities in water and sediment can have different capacity to degrade such compounds.

Research on WWTP sludge has demonstrated that ion trapping of amines in protozoa can reduce the available concentration of positively charged chemicals in the water phase, ${ }^{73}$ with the consequence that the dissipation rate of tramadol and venlafaxine (containing an amine functional group) may be misinterpreted as biotransformation. In this study, TPs of both tramadol and venlafaxine were detected at higher levels than in the respective unamended controls (UC), but the time trends differed between the compounds. There was a clear increase of desmethyltramadol in $\mathrm{H}$ and $\mathrm{L}$ treatments as well as in the sterilized controls for the River Fyris sediments (Figure 2), the sediments in which tramadol disappeared the fastest (Table 1). In both River Gründlach sediments, the levels of desmethyltramadol were lower, which agrees with the slower dissipation of tramadol observed particularly in G2. The TP of venlafaxine, o-desmethylvenlafaxine, was detected consistently in samples collected immediately after addition of the micropollutant mixture, but the increase in concentration was less distinct than for desmethyltramadol (Figure 2). The levels of o-desmethylvenlafaxine in the $\mathrm{H}$ and $\mathrm{L}$ treatments were higher than in the UC in support of degradation occurring in the amended treatments. In river Gründlach, both desmethyltramadol and o-desmethylvenlafaxine increased at a slower rate $(\mathrm{H})$ or increased during the first 7 days and then decreased (L), suggesting further degradation of both TPs. Hence, the biodegradation of tramadol and venlafaxine was supported by the data on transformation products, and ion trapping in protozoa does not seem to be a significant process explaining decreasing concentrations of these two compounds in the incubations.

Faster Dissipation of Diclofenac and Metformin at Low Amended Concentrations. The DT50 for diclofenac was significantly lower at the low concentration level, as well as in Gründlach sediments compared to Fyris sediments. Diclofenac is susceptible to photodegradation, which was hypothesized to be the relevant driver of the $60 \%$ dissipation previously observed in situ in River Gründlach. ${ }^{33,74}$ Our study was performed in the dark and therefore photolysis can be excluded. Hence, our 


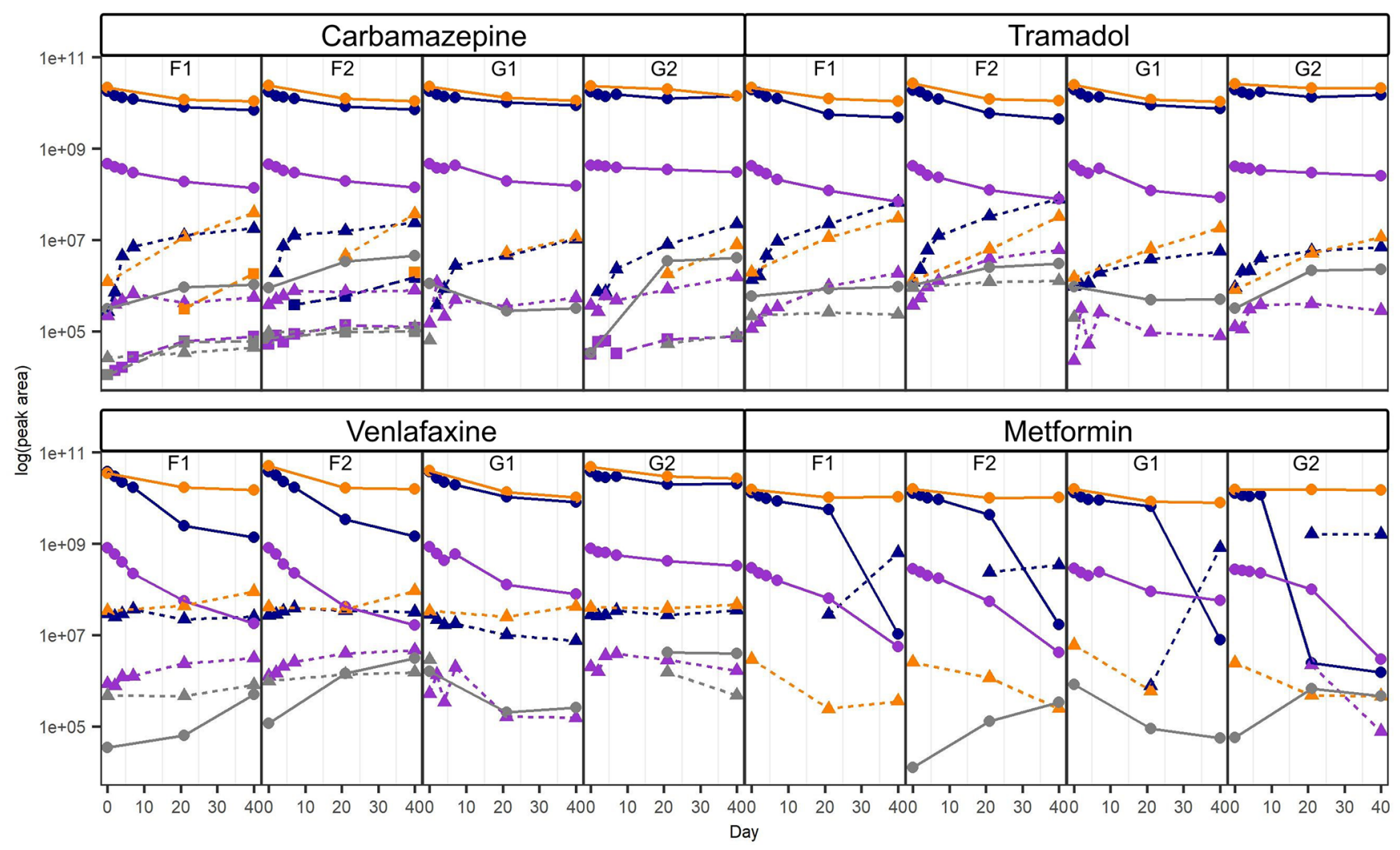

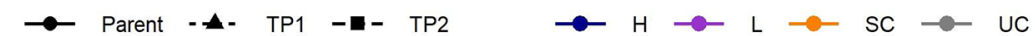

Figure 2. Time series of peak areas of parent compounds carbamazepine, tramadol, venlafaxine, and metformin and their corresponding transformation products (TPs; 10,11-dihydro-10,11-dihydroxycarbamazepine, carbamazepine 10,11-epoxide, desmethyltramadol, o-desmethylvenlafaxine, and guanylurea), which were measured in one replicate of the high $(\mathrm{H})$ and low $(\mathrm{L})$ concentration incubations, the sediment control (SC) and the unamended control (UC). The symbol of TP2 is only used for carbamazepine 10,11- epoxide.

data support previous findings of bacterial degradation of diclofenac. $^{75}$

Dissipation of metformin was significantly different between the sediment from the two rivers and between concentrations, with faster dissipation in Fyris and at low concentrations. Other studies have also found differences in metformin dissipation and suggested that biodegradability depends on bacterial adaptation. $^{58,76-79}$ A major TP of metformin, guanyl urea, was detected in all sediments at the high concentration $(\mathrm{H})$ (Figure 2). The increasing trend of guanyl urea over time agrees with the decreasing concentration of the parent compound metformin, supporting the ongoing bacterial degradation of metformin in the $\mathrm{H}$ system.

Acetaminophen, Caffeine, and Furosemide Showed No Differences in Dissipation between the Sediments. Neither river nor location effects were significant for the compounds with the lowest DT50s in the sediment-water incubations: acetaminophen (DT50s $<4$ days), caffeine (DT50s $<10$ days) and furosemide (DT50s 6-84 days). Fast dissipation could indicate that bacteria capable of degrading these compounds were ubiquitously present. No dissipation of acetaminophen was observed previously in Fyris, ${ }^{33}$ but caffeine was not included in the previous study. Acetaminophen and caffeine have dissipated fast in previous experimental studies with DT50s of $1-28$ days $^{41,59,80}$ and $2-13$ days, ${ }^{15,59,67}$ respectively. Acetaminophen was the only compound with dissipation in the deionized water control (Table 1), indicating that hydrolysis contributes to the overall dissipation observed in the treatments, in congruence with previous results. ${ }^{15}$ In the previous field study, furosemide had the highest removal in river Gründlach ${ }^{33}$ but this was not observed in our study. However, degradation by photolysis could be relevant for furosemide in the field, ${ }^{81}$ which would agree with fast removal in the shallow river Gründlach compared to the deeper river Fyris with higher turbidity and less light penetration depth. As furosemide had substantial dissipation in the sterile control (SI Table S9), this compound could be degraded by bacteria present in the control or be subject to sorption in the sediment.

Implications of Normalization of DT50 Values by RNA Concentration. Previous biodegradation studies in activated sludge with normalized DT50s have used TOC, particulate organic carbon or total suspended solids as estimate of biomass. Biomass is used for normalization under the assumption that the fraction of degraders in all sediments is proportional to the overall biomass. It would be preferable to use the abundance of the degraders, functional biomass, or enzyme concentration, ${ }^{82}$ but as this information is not available for most micropollutants, it is currently not possible to calculate normalized DT50s with higher specificity. In this study, total RNA concentration was used to estimate the extracted active microbial biomass for normalization of DT50s, though there are limitations of this approach $^{83}$ including differences in mRNA transcription and RNA degradation rates. The RNA concentrations in the sample extracts were $>10$ times lower in G2 compared to G1, F1, and 


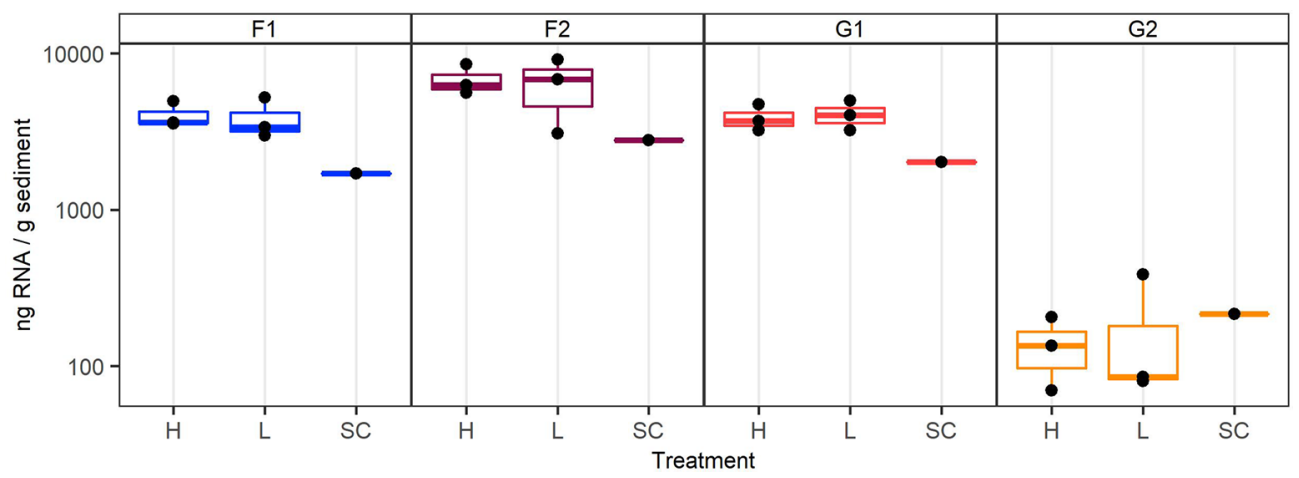

Figure 3. RNA concentration in the extracts from sediments exposed to high concentration $(\mathrm{H})$, low concentration $(\mathrm{L})$, and in the sterilized control (SC). The labels F1, F2, G1, and G2 correspond to the sampling locations: River Fyris or River Gründlach, upstream or downstream the WWTP.

F2 (Figures 1B and 3), thus G2 has the lowest estimated biomass. The concentrations of TOC, nitrate/nitrite and ammonium (SI Table S1) were also lower in G2 compared to G1 and the sediment from the two sites in River Fyris (F1 and $\mathrm{F} 2$ ). Low levels of $\mathrm{C}$ and $\mathrm{N}$ were likely to limit the biomass production in G2.

Because of the lower concentrations of RNA in sediment G2, the DT50norm values of all compounds were significantly lower in G2 compared to F1, F2 and G1 $(p<0.05$, SI Table S16). Significant overall differences in DT50norm between the two rivers, locations, and concentrations (rankMANOVA: $p<0.05$, SI Table S13) were observed. The RSDs of DT50norm were more homogeneous, ranging from 70 to $85 \%$ for most compounds (acetaminophen, acesulfame, caffeine, furosemide, metformin, oxazepam, and venlafaxine, Table 1), but were not generally lower than RSDs of raw DT50s. In contrast to our results, previous studies have proposed that normalization to biomass leads to DT50s that are more robust because higher biomass levels can lead to higher biodegradation. 9,44,84,85

Bacterial Communities in Sediment Based on $16 \mathrm{~S}$ rRNA Amplicon Sequences. Bacterial Community Diversity and Composition. The Fisher's alpha and Shannon indices (Figure 4A) representing taxonomic diversity did not differ significantly between the rivers, locations and concentration levels (ANOVA: $p<0.05$, SI Table S19 and S20). The taxonomic diversity of bacterial communities in the sediment used in this study did not correlate to the differences in dissipation capacity of micropollutants: fast dissipation occurred in sediment G2 (normalized DT50s), but the corresponding bacterial community did not have higher diversity than in sediments F1, F2, or G1. In contrast to our observations, higher diversity resulted in increased dissipation of 20 out of 31 micropollutants in a study with recirculating flumes. ${ }^{30,31}$ In the flume study, ${ }^{31}$ it is possible, however, that the taxonomic diversity of the sediment bacterial communities was correlated to the functional diversity because the range in diversity was created by diluting one sediment with sand (using the "dilution to extinction" approach). In the present study, the taxonomic diversity was instead the result of sediment sampled in different rivers and locations within the river. As functional diversity may be more representative of increased dissipation of micropollutants, one reason for the lack of a correlation between taxonomic diversity and micropollutant dissipation in our study could stem from a lack of relationship between the taxonomic and functional diversity. ${ }^{86,87}$

Despite similar diversity indices, overall bacterial community composition differed across sample types (PERMANOVA:
$\mathrm{F}_{7,15}=4.63, p=0.001$, between rivers $\left.\mathrm{F}_{1,19}=13.7, p=0.001\right)$ and differed significantly between the rivers (Figure 4B, SI Figure S4). Moreover, community composition in River Gründlach differed between the locations (perMANOVA, $\left.\mathrm{F}_{1,19}=5.28, p=0.005\right)$, whereas location was not a significant factor in River Fyris (Figure 4B). Thus, the fast dissipation of micropollutants in sediment G2 compared to F1, F2, and G1, could not be completely explained by differences in diversity nor biomass (with RNA concentration as a proxy for biomass), but it could be associated with differences in bacterial community composition. The differences in bacterial community composition between rivers and locations could be driven by various factors such as temperature, hydrology, nutrient load or the quality of organic matter. ${ }^{88}$ Nutrient levels (SI Table S1) were indeed different between River Fyris (F1 and F2) and the sites in River Gründlach (G1 and G2), with TOC being substantially lower in G2. One additional factor influencing the bacterial community could be the input of WWTP discharge in river Gründlach. Bacterial communities downstream of WWTPs are continuously exposed to micropollutants, bacteria from the activated sludge as well as high nutrient and organic carbon loads through wastewater. Each of these parameters can alter bacterial community composition and degradation capacity compared to the less exposed upstream communities. ${ }^{89,90}$

Differential Abundance of Bacteria and Links to Dissipation of Micropollutants. Further analysis of $\mathrm{DT}_{50} \mathrm{norm}_{\text {and }}$ anderial community composition was performed with the assumption that fast dissipation occurs partly because some of the bacteria with higher representation contribute to the biodegradation of micropollutants. Overrepresented bacteria could either contribute directly to biodegradation through the production of enzymes able to transform the micropollutants, or indirectly by providing complementary functions to the bacterial community which enable biodegradation. There were 826 bacterial ASVs which had significantly different relative abundances ( $\log 2$ fold change $>|2|$ and $p$-adjusted $<0.05$ ) between the G2 sediment (where the fast dissipation was observed) and the F1, F2, and G1 sediments (which had slower dissipation) (SI Table S21). About one-third of these ASVs were significantly more abundant in G2 $(n=281, \log 2$ fold-change $>2)$ and the remaining ASVs were more abundant in F1, F2, and G1 $(n=545, \log 2$ fold-change $<2)$.

One ASV of the genus Pseudomonas was significantly more abundant in G2 sediment and has been associated in the literature with biodegradation of carbamazepine and acetaminophen (see SI Table S4), as well as atrazine and polycyclic aromatic hydrocarbons. ${ }^{91,92}$ The genera Hyphomicrobium and 
A

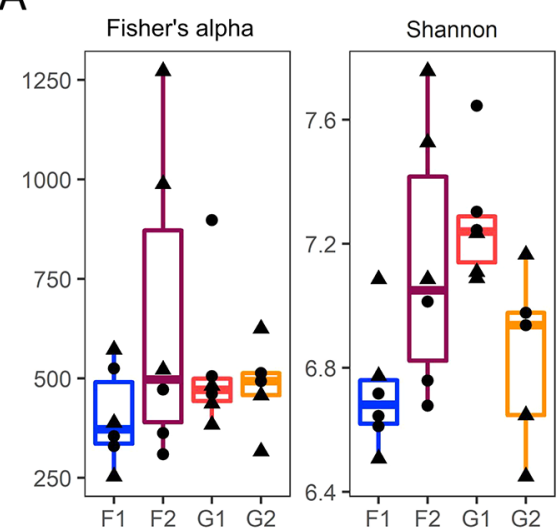

B

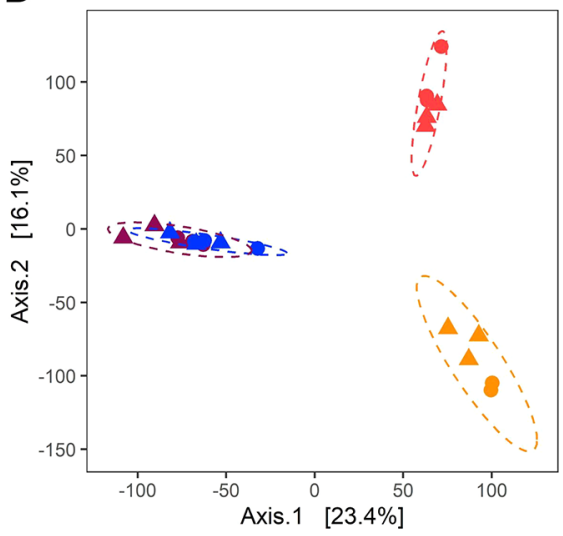

C

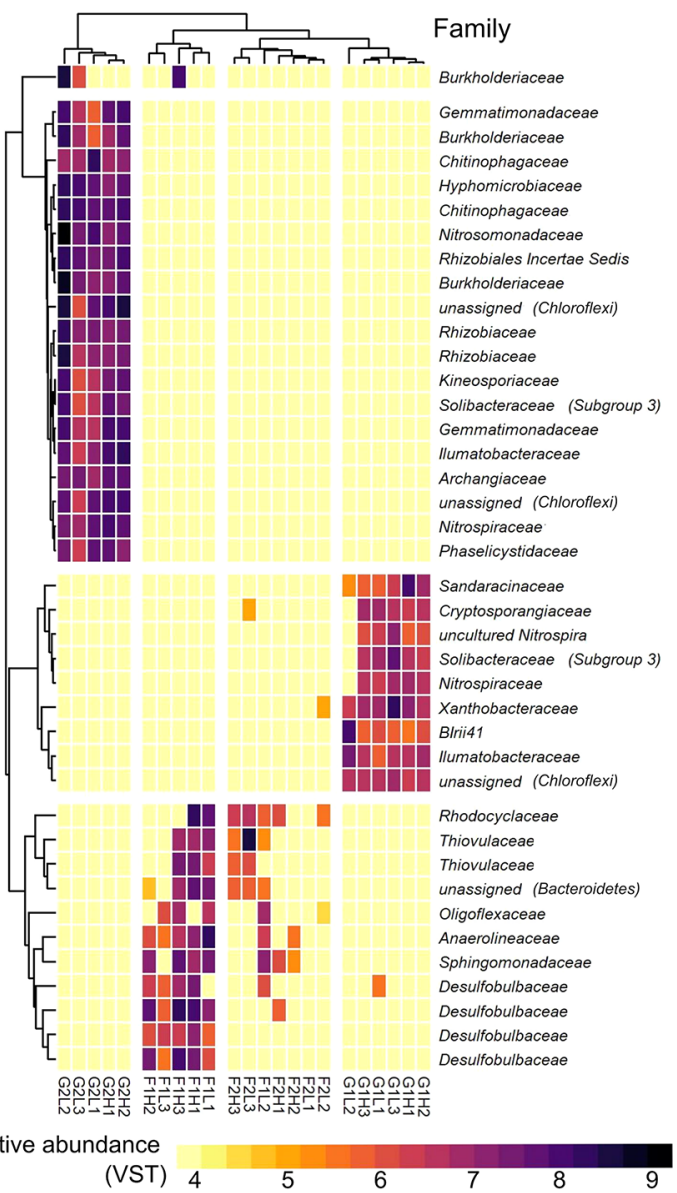

Figure 4. Bacterial community characteristics based on 16S rRNA gene sequences: (A) Fisher's alpha and Shannon diversity indices; (B) PCoA based on Euclidian distance; (C) heat map showing the relative abundance (with variance stabilizing transformation - VST) of the 20 ASVs with the highest and lowest fold-change. The ASV Family was used as a label and if unavailable, the Phylum is listed in parentheses.

Novosphingobium, both associated with degradation of hydrocarbons, ${ }^{93,94}$ also had overrepresented ASVs in G2 (8 and 6 ASVs, respectively). Two overrepresented ASVs in G2 of the genus Ralstonia, family Burkholderiaceae, are also prominent: one had the highest relative abundance (10\%) in G2, and one had the highest fold change $\left(\log _{2}\right.$ fold-change $\left.=25.8\right)$. Members of this genus, such as Ralstonia pikketti, Ralstonia eutropha, and Ralstonia basilens, are known to biodegrade organic pollutants. ${ }^{95-97}$ Overall, the family Burkholderiaceae, with 20 ASVs that were more than 100 -fold abundant at G2, contains environmental saprophytic bacteria, which could be relevant for micropollutant degradation. ${ }^{98}$ Other overrepresented families in G2 ( $\log 2$ fold-change $>7$ ) included several aerobic bacteria which have been found in soil or WWTPs (e.g., Gemmatimonadaceae and Chthoniobacteraceae), aerobic chemoorganotrophic bacteria (e.g., Rhizobiaceae, Ilumatobacteraceae, some of which have been associated with dissipation of organic contaminants) and bacteria involved in the nitrogen cycle (e.g., ammonia oxidizers from Nitrosomonadaceae and the nitriteoxidizers from oxidizing Nistrospiraceae). ${ }^{98}$ Most of the overrepresented ASVs in sediment G2 did not have an assigned taxonomic family (79) or genus (146).

The higher relative abundance of possible micropollutant degraders in G2 compared to G1, F1, and F2, supports the finding that fast dissipation of micropollutants (especially acesulfame-K) occurred in G2. Although other sediment characteristics were different in G2, the lower concentrations of TOC and nitrogen compounds (SI Table S1) are not expected to be associated with higher dissipation capacity. ${ }^{67}$ Micropollutant dissipation capacity of freshwater sediments can be seen as an ecosystem function. Bacterial community structure can be decoupled from environmental conditions (e.g., $\mathrm{pH}$, temperature, nutrient and carbon content), and thus the use of diversity or community structure in addition to environmental variables has improved the prediction of ecosystem functions, such as $\mathrm{N}$ and $\mathrm{C}$ cycling, ${ }^{99,100}$ as well as micropollutant dissipation. However, the understanding of how ecosystem functions are determined by bacterial community structure remains limited. ${ }^{101,102}$

Overall Association between DT50s and Bacterial Community Composition. Our findings demonstrate that there can be an association of the sediments' dissipating capacity of micropollutants and bacterial community composition, thus affecting DT50s generated for regulatory purposes with the OECD standard. The variation in the non-normalized DT50s is enough to affect the persistence assessment of a compound, especially when a single DT50 is compared to threshold criteria (e.g., REACH cutoff value for sediment of 120 days). This finding calls for better-defined boundaries on standard tests such as the OECD 308. Interpretation of normalized DT50s is currently difficult in the context of regulation due to lack of threshold criteria. Normalization of the DT50s to RNA 
concentrations did not reduce the variability among DT50s but does correct for variability due to biomass, thus providing information on the role of bacterial community composition for the sediment's dissipation capacity. Sediment from River Grünlach downstream of the WWTP consistently had the highest dissipating capacity for all micropollutants after correcting for RNA concentrations in the sediment. The sediment from River Gründlach also had a higher relative abundance of potential micropollutant degraders. The influence of bacterial communities has so far been overlooked when interpreting DT50s of micropollutants, but our findings show that the observed intracompound differences between "fast" and "slow" dissipation may be at least partially attributed to the differences in the bacterial community composition of the sediment. The microbial community consists not only of bacteria, and thus the contribution of other organisms to the DT50 variability needs to be investigated further if we are to understand the biodegradation capacity of sediments. Although challenging, it is crucial to combine theory and methods from several disciplines to generate knowledge that contributes to better understanding of the complex processes and interactions that micropollutants undergo in the environment. The associations between community structure and DT50 that are presented in this study are correlative, and more research is needed to identify the bacteria driving environmental dissipation of micropollutants, and to better understand how to extrapolate results from laboratory experiments to environmental systems. Our findings can help to generate hypotheses on the roles of bacterial community diversity and structure on the dissipation of chemicals, and, ultimately, on how environmental stressors affect bacterial community diversity and composition.

\section{ASSOCIATED CONTENT}

\section{SI Supporting Information}

The Supporting Information is available free of charge at https://pubs.acs.org/doi/10.1021/acs.est.0c04393.

study sites and sediment characteristics; chemicals and reagents; analytical method for determining micropollutant concentrations; aeration, dissolved oxygen and pH measurements; 16SrRNA analysis and sequence processing, DT50s of all test systems and replicates; rank-based MANOVA of DT50s; ANOVA of Shannon and Fisher's alpha diversity indices; bacterial community composition of sediment and water, differential abundance of ASVs; The 16S rRNA sequence reads obtained are publicly available in the EMBL European Nucleotide Archive (https://www.ebi.ac.uk/ena) under project number PRJEB26608. Other data sets generated during and/ or analyzed during the current study are available from the corresponding author on reasonable request (PDF)

\section{AUTHOR INFORMATION}

\section{Corresponding Author}

Claudia Coll - Department of Environmental Science (ACES), Stockholm University, 10691 Stockholm, Sweden; Eawag, Swiss Federal Institute of Aquatic Science and Technology, 8600 Dübendorf, Switzerland; 이이.org/0000-0003-1100-1263; Email: claudia.coll@eawag.ch

\section{Authors}

Raven Bier - Department of Ecology and Genetics/Limnology, Uppsala University, 75236 Uppsala, Sweden; Stroud Water Research Center, Avondale, Pennsylvania 19311, United States

Zhe Li - Department of Environmental Science (ACES), Stockholm University, 10691 Stockholm, Sweden; 이이.org/ 0000-0002-2379-0768

Silke Langenheder - Department of Ecology and Genetics/ Limnology, Uppsala University, 75236 Uppsala, Sweden

Elena Gorokhova - Department of Environmental Science (ACES), Stockholm University, 10691 Stockholm, Sweden

Anna Sobek - Department of Environmental Science (ACES), Stockholm University, 10691 Stockholm, Sweden; ㅇ orcid.org/ 0000-0002-1549-7449

Complete contact information is available at:

https://pubs.acs.org/10.1021/acs.est.0c04393

\section{Author Contributions}

C.C. and A.S. conceived and designed the study. C.C. and Z.L. performed chemical analyses. C.C. and R.B. performed microbiological analyses. C.C. analyzed the data with contributions from R.B. and E.G. C.C, R.B., Z.L., E.G., S.L., and A.S. interpreted results. C.C. and A.S. wrote manuscript, with contributions from R.B., Z.L., E.G., and S.L.

\section{Notes}

The authors declare no competing financial interest.

\section{ACKNOWLEDGMENTS}

This project has received funding from the European Union's Horizon 2020 research and innovation programme under the Marie Sklodowska-Curie grant agreement No 641939 and from Stockholm University. Thank you to Robin Hagblom for assistance with molecular work and to Dr Jürg Brendan Logue for constructive discussions at an early stage of the study, and anonymous reviewers for constructive comments on an earlier version of the manuscript. Sequencing was performed by the SNP\&SEQ Technology Platform in Uppsala. The facility is part of the National Genomics Infrastructure (NGI) Sweden and Science for Life Laboratory. The SNP\&SEQ Platform is also supported by the Swedish Research Council and the Knut and Alice Wallenberg Foundation.

\section{REFERENCES}

(1) Cousins, I. T.; Ng, C. A.; Wang, Z.; Scheringer, M. Why is high persistence alone a major cause of concern? Environ. Sci. Process Impacts 2019, 21 (5), 781-792.

(2) Larson, R. J.; Cowan, C. E. Quantitative Application of Biodegradation Data to Environmental Risk and Exposure Assessments. Environ. Toxicol. Chem. 1995, 14 (8), 1433-1442.

(3) Schwarzenbach, R. P.; Escher, B. I.; Fenner, K.; Hofstetter, T. B.; Johnson, C. A.; von Gunten, U.; Wehrli, B. The Challenge of Micropollutants in Aquatic Systems. Science 2006, 313 (5790), 10721077.

(4) Francois, B.; Armand, M.; Marie-Jose, D.; Thouand, G. From laboratory to environmental conditions: a new approach for chemical's biodegradability assessment. Environ. Sci. Pollut. Res. 2016, 23 (18), 18684-93.

(5) Honti, M.; Bischoff, F.; Moser, A.; Stamm, C.; Baranya, S.; Fenner, K. Relating Degradation of Pharmaceutical Active Ingredients in a Stream Network to Degradation in Water-Sediment Simulation Tests. Water Resour. Res. 2018, 54 (11), 9207-9223.

(6) OECD. Test No. 308: Aerobic and Anaerobic Transformation in Aquatic Sediment Systems; OECD Publishing: Paris, 2002. 
(7) ECHA. Guidance on Information Requirements and Chemical Safety Assessment. Chapter R.11: PBT/vPvB assessment; European Chemical Agency: Helsinki, Finland, 2017.

(8) Ericson, J. F. An evaluation of the OECD 308 water/sediment systems for investigating the biodegradation of pharmaceuticals. Environ. Sci. Technol. 2007, 41 (16), 5803-11.

(9) Honti, M.; Hahn, S.; Hennecke, D.; Junker, T.; Shrestha, P.; Fenner, K. Bridging across OECD 308 and 309 Data in Search of a Robust Biotransformation Indicator. Environ. Sci. Technol. 2016, 50 (13), 6865-6872.

(10) Honti, M.; Fenner, K. Deriving persistence indicators from regulatory water-sediment studies - opportunities and limitations in OECD 308 data. Environ. Sci. Technol. 2015, 49 (10), 5879-86.

(11) Shrestha, P.; Junker, T.; Fenner, K.; Hahn, S.; Honti, M.; Bakkour, R.; Diaz, C.; Hennecke, D. Simulation Studies to Explore Biodegradation in Water-Sediment Systems: From OECD 308 to OECD 309. Environ. Sci. Technol. 2016, 50 (13), 6856-6864.

(12) Radke, M.; Maier, M. P. Lessons learned from water/sedimenttesting of pharmaceuticals. Water Res. 2014, 55, 63-73.

(13) Helbling, D. E.; Hammes, F.; Egli, T.; Kohler, H. P. Kinetics and yields of pesticide biodegradation at low substrate concentrations and under conditions restricting assimilable organic carbon. Appl. Environ. Microbiol. 2014, 80 (4), 1306-13.

(14) Kundu, K.; Marozava, S.; Ehrl, B.; Merl-Pham, J.; Griebler, C.; Elsner, M. Defining lower limits of biodegradation: atrazine degradation regulated by mass transfer and maintenance demand in Arthrobacter aurescens TC1. ISME J. 2019, 13 (9), 2236-2251.

(15) Li, Z.; McLachlan, M. S. Biodegradation of Chemicals in Unspiked Surface Waters Downstream of Wastewater Treatment Plants. Environ. Sci. Technol. 2019, 53 (4), 1884-1892.

(16) Poursat, B. A. J.; van Spanning, R. J. M.; de Voogt, P.; Parsons, J. R. Implications of microbial adaptation for the assessment of environmental persistence of chemicals. Crit. Rev. Environ. Sci. Technol. 2019, 49, 1-36.

(17) Hammershoj, R.; Birch, H.; Redman, A. D.; Mayer, P. Mixture Effects on Biodegradation Kinetics of Hydrocarbons in Surface Water: Increasing Concentrations Inhibited Degradation whereas Multiple Substrates Did Not. Environ. Sci. Technol. 2019, 53 (6), 3087-3094.

(18) Kim, S.; Rossmassler, K.; Broeckling, C. D.; Galloway, S.; Prenni, J.; De Long, S. K. Impact of inoculum sources on biotransformation of pharmaceuticals and personal care products. Water Res. 2017, 125, 227-236.

(19) Rieger, P. G.; Meier, H. M.; Gerle, M.; Vogt, U.; Groth, T.; Knackmuss, H. J. Xenobiotics in the environment: present and future strategies to obviate the problem of biological persistence. J. Biotechnol. 2002, 94 (1), 101-23.

(20) Copley, S. D. Evolution of efficient pathways for degradation of anthropogenic chemicals. Nat. Chem. Biol. 2009, 5, 559.

(21) Udiković-Kolić, N.; Scott, C.; Martin-Laurent, F. Evolution of atrazine-degrading capabilities in the environment. Appl. Microbiol. Biotechnol. 2012, 96 (5), 1175-1189.

(22) Loreau, M.; Naeem, S.; Inchausti, P.; Bengtsson, J.; Grime, J. P.; Hector, A.; Hooper, D. U.; Huston, M. A.; Raffaelli, D.; Schmid, B.; Tilman, D.; Wardle, D. A. Biodiversity and Ecosystem Functioning: Current Knowledge and Future Challenges. Science 2001, 294 (5543), 804-808.

(23) Battin, T. J.; Besemer, K.; Bengtsson, M. M.; Romani, A. M.; Packmann, A. I. The ecology and biogeochemistry of stream biofilms. Nat. Rev. Microbiol. 2016, 14 (4), 251-63.

(24) Baschien, C.; Manz, W.; Neu, T. R.; Marvanova, L.; Szewzyk, $\mathrm{U}$. In situ detection of freshwater fungi in an alpine stream by new taxon-specific fluorescence in situ hybridization probes. Appl. Environ. Microbiol. 2008, 74 (20), 6427-36.

(25) Buriánková, I.; Brablcová, L.; Mach, V.; Dvořák, P.; Chaudhary, P. P.; Rulík, M. Identification of methanogenic archaea in the hyporheic sediment of Sitka stream. PLoS One 2013, 8 (11), No. e80804-e80804.

(26) Lewandowski, J. A. S.; Banks, E.; Batelaan, O.; Betterle, A.; Broecker, T.; Coll, C.; Drummond, J. D.; Gaona Garcia, J.; Galloway,
J.; Gomez-Velez, J.; Grabowski, R. C.; Herzog, S. P.; Hinkelmann, R.; Höhne, A.; Hollender, J.; Horn, M. A.; Jaeger, A.; Krause, S.; Löchner Prats, A.; Magliozzi, C.; Meinikmann, K.; Mojarrad, B. B.; Mueller, B. M.; Peralta-Maraver, I.; Popp, A. L.; Posselt, M.; Putschew, A.; Radke, M.; Raza, M.; Riml, J.; Robertson, A.; Rutere, C.; Schaper, J. L.; Schirmer, M.; Schulz, H.; Shanafield, M.; Singh, T.; Ward, A. S.; Wolke, P.; Wörman, A.; Wu, L. Is the Hyporheic Zone Relevant beyond the Scientific Community? Water 2019, 11 (11), 2230.

(27) Ochman, H.; Lawrence, J. G.; Groisman, E. A. Lateral gene transfer and the nature of bacterial innovation. Nature 2000, 405 (6784), 299-304.

(28) Johnson, D. R.; Helbling, D. E.; Lee, T. K.; Park, J.; Fenner, K.; Kohler, H. P.; Ackermann, M. Association of biodiversity with the rates of micropollutant biotransformations among full-scale wastewater treatment plant communities. Appl. Environ. Microbiol. 2015, 81 (2), 666-75.

(29) Stadler, L. B.; Vela, J. D.; Jain, S.; Dick, G. J.; Love, N. G. Elucidating the impact of microbial community biodiversity on pharmaceutical biotransformation during wastewater treatment. Microb. Biotechnol. 2018.11995

(30) Jaeger, A.; Coll, C.; Posselt, M.; Mechelke, J.; Rutere, C.; Betterle, A.; Raza, M.; Mehrtens, A.; Meinikmann, K.; Portmann, A.; Singh, T.; Blaen, P. J.; Krause, S.; Horn, M. A.; Hollender, J.; Benskin, J. P.; Sobek, A.; Lewandowski, J. Using recirculating flumes and a response surface model to investigate the role of hyporheic exchange and bacterial diversity on micropollutant half-lives. Environ. Sci. Process Impacts 2019, 21 (12), 2093-2108.

(31) Posselt, M.; Mechelke, J.; Rutere, C.; Coll, C.; Jaeger, A.; Raza, M.; Meinikmann, K.; Krause, S.; Sobek, A.; Lewandowski, J.; Horn, M. A.; Hollender, J.; Benskin, J. P. Bacterial Diversity Controls Transformation of Wastewater-Derived Organic Contaminants in River-Simulating Flumes. Environ. Sci. Technol. 2020, 54 (9), 54675479.

(32) Zhang, M.; Yu, N.; Chen, L.; Jiang, C.; Tao, Y.; Zhang, T.; Chen, J.; Xue, D. Structure and seasonal dynamics of bacterial communities in three urban rivers in China. Aquat. Sci. 2012, 74 (1), $113-120$.

(33) Li, Z.; Sobek, A.; Radke, M. Fate of Pharmaceuticals and Their Transformation Products in Four Small European Rivers Receiving Treated Wastewater. Environ. Sci. Technol. 2016, 50 (11), 5614-21.

(34) Aydin, E.; Talinli, I. Analysis, occurrence and fate of commonly used pharmaceuticals and hormones in the Buyukcekmece Watershed, Turkey. Chemosphere 2013, 90 (6), 2004-2012.

(35) Loos, R.; Gawlik, B. M.; Locoro, G.; Rimaviciute, E.; Contini, S.; Bidoglio, G. EU-wide survey of polar organic persistent pollutants in European river waters. Environ. Pollut. 2009, 157 (2), 561-8.

(36) Larsson, D. G.; de Pedro, C.; Paxeus, N. Effluent from drug manufactures contains extremely high levels of pharmaceuticals. $J$. Hazard. Mater. 2007, 148 (3), 751-5.

(37) Callahan, B. J.; McMurdie, P. J.; Rosen, M. J.; Han, A. W.; Johnson, A. J. A.; Holmes, S. P. DADA2: High-resolution sample inference from Illumina amplicon data. Nat. Methods 2016, 13 (7), $581-583$.

(38) Bolyen, E.; Rideout, J. R.; Dillon, M. R.; Bokulich, N. A.; Abnet, C. C.; Al-Ghalith, G. A.; Alexander, H.; Alm, E. J.; Arumugam, M.; Asnicar, F.; Bai, Y.; Bisanz, J. E.; Bittinger, K.; Brejnrod, A.; Brislawn, C. J.; Brown, C. T.; Callahan, B. J.; Caraballo-Rodríguez, A. M.; Chase, J.; Cope, E. K.; Da Silva, R.; Diener, C.; Dorrestein, P. C.; Douglas, G. M.; Durall, D. M.; Duvallet, C.; Edwardson, C. F.; Ernst, M.; Estaki, M.; Fouquier, J.; Gauglitz, J. M.; Gibbons, S. M.; Gibson, D. L.; Gonzalez, A.; Gorlick, K.; Guo, J.; Hillmann, B.; Holmes, S.; Holste, H.; Huttenhower, C.; Huttley, G. A.; Janssen, S.; Jarmusch, A. K.; Jiang, L.; Kaehler, B. D.; Kang, K. B.; Keefe, C. R.; Keim, P.; Kelley, S. T.; Knights, D.; Koester, I.; Kosciolek, T.; Kreps, J.; Langille, M. G. I.; Lee, J.; Ley, R.; Liu, Y.-X.; Loftfield, E.; Lozupone, C.; Maher, M.; Marotz, C.; Martin, B. D.; McDonald, D.; McIver, L. J.; Melnik, A. V.; Metcalf, J. L.; Morgan, S. C.; Morton, J. T.; Naimey, A. T.; Navas-Molina, J. A.; Nothias, L. F.; Orchanian, S. B.; Pearson, T.; Peoples, S. L.; Petras, D.; Preuss, M. L.; Pruesse, E.; Rasmussen, L. 
B.; Rivers, A.; Robeson, M. S.; Rosenthal, P.; Segata, N.; Shaffer, M.; Shiffer, A.; Sinha, R.; Song, S. J.; Spear, J. R.; Swafford, A. D.; Thompson, L. R.; Torres, P. J.; Trinh, P.; Tripathi, A.; Turnbaugh, P. J.; Ul-Hasan, S.; van der Hooft, J. J. J.; Vargas, F.; Vázquez-Baeza, Y.; Vogtmann, E.; von Hippel, M.; Walters, W.; Wan, Y.; Wang, M.; Warren, J.; Weber, K. C.; Williamson, C. H. D.; Willis, A. D.; Xu, Z. Z.; Zaneveld, J. R.; Zhang, Y.; Zhu, Q.; Knight, R.; Caporaso, J. G. Reproducible, interactive, scalable and extensible microbiome data science using QIIME 2. Nat. Biotechnol. 2019, 37 (8), 852-857.

(39) Martin, M. Cutadapt removes adapter sequences from highthroughput sequencing reads. 2011 2011, 17 (1), 3.

(40) Quast, C.; Pruesse, E.; Yilmaz, P.; Gerken, J.; Schweer, T.; Yarza, P.; Peplies, J.; Glöckner, F. O. The SILVA ribosomal RNA gene database project: improved data processing and web-based tools. Nucleic Acids Res. 2012, 41 (Database issue), D590-D596.

(41) Li, Z.; Sobek, A.; Radke, M. Flume experiments to investigate the environmental fate of pharmaceuticals and their transformation products in streams. Environ. Sci. Technol. 2015, 49 (10), 6009-17.

(42) Ranke, J.; Lindenberger, K.; Lehmann, R. mkin Package: Kinetic Evaluation of Chemical Degradation Data, version 0.9.47.5; 2018.

(43) R Development Core Team. R: A language and environment for statistical computing.; R Foundation for Statistical Computing: Vienna, Austria, 2008.

(44) Fenner, K.; Screpanti, C.; Renold, P.; Rouchdi, M.; Vogler, B.; Rich, S. Comparison of Small Molecule Biotransformation Half-Lives between Activated Sludge and Soil: Opportunities for Read-Across? Environ. Sci. Technol. 2020, 54 (6), 3148-3158.

(45) Li, Z.; Undeman, E.; Papa, E.; McLachlan, M. S. Highthroughput evaluation of organic contaminant removal efficiency in a wastewater treatment plant using direct injection UHPLC-OrbitrapMS/MS. Environ. Sci. Process Impacts 2018, 20 (3), 561-571.

(46) Schymanski, E. L.; Jeon, J.; Gulde, R.; Fenner, K.; Ruff, M.; Singer, H. P.; Hollender, J. Identifying small molecules via high resolution mass spectrometry: communicating confidence. Environ. Sci. Technol. 2014, 48 (4), 2097-8.

(47) Dobler, D.; Friedrich, S.; Pauly, M. Nonparametric MANOVA in meaningful effects. Annals of the Institute of Statistical Mathematics 2020, 72 (4), 997-1022.

(48) McMurdie, P. J.; Holmes, S. phyloseq: An R Package for Reproducible Interactive Analysis and Graphics of Microbiome Census Data. PLoS One 2013, 8 (4), No. e61217.

(49) Oksanen, J.; Blanchet, F. G.; Friendly, M.; Kindt, R.; Legendre, P.; McGlinn, D.; Minchin, P. R.; O’Hara, R. B.; Simpson, G. L.; Solymo, P.; Steens, M. H. H.; Szoecs, E.; Wagner, H. Vegan: Community Ecology Package, version 2.5-2; 2018.

(50) Anderson, M. J. A new method for non-parametric multivariate analysis of variance. Austral Ecology 2001, 26 (1), 32-46.

(51) Love, M. I.; Huber, W.; Anders, S. Moderated estimation of fold change and dispersion for RNA-seq data with DESeq2. Genome Biol. 2014, 15 (12), 550.

(52) McMurdie, P. J.; Holmes, S. Waste Not, Want Not: Why Rarefying Microbiome Data Is Inadmissible. PLoS Comput. Biol. 2014, 10 (4), No. e1003531.

(53) Zou, H.; Radke, M.; Kierkegaard, A.; MacLeod, M.; McLachlan, M. S. Using chemical benchmarking to determine the persistence of chemicals in a Swedish lake. Environ. Sci. Technol. 2015, 49 (3), 1646-53.

(54) Kahl, S.; Kleinsteuber, S.; Nivala, J.; van Afferden, M.; Reemtsma, T. Emerging Biodegradation of the Previously Persistent Artificial Sweetener Acesulfame in Biological Wastewater Treatment. Environ. Sci. Technol. 2018, 52 (5), 2717-2725.

(55) Kleinsteuber, S.; Rohwerder, T.; Lohse, U.; Seiwert, B.; Reemtsma, T. Sated by a Zero-Calorie Sweetener: Wastewater Bacteria Can Feed on Acesulfame. Front. Microbiol. 2019, 10, (2606). DOI: $10.3389 /$ fmicb.2019.02606

(56) LaPara, T. M.; Burch, T. R.; McNamara, P. J.; Tan, D. T.; Yan, M.; Eichmiller, J. J. Tertiary-treated municipal wastewater is a significant point source of antibiotic resistance genes into DuluthSuperior Harbor. Environ. Sci. Technol. 2011, 45 (22), 9543-9.
(57) Marti, E.; Jofre, J.; Balcazar, J. L. Prevalence of Antibiotic Resistance Genes and Bacterial Community Composition in a River Influenced by a Wastewater Treatment Plant. PLoS One 2013, 8 (10), No. e78906.

(58) Jaeger, A.; Posselt, M.; Betterle, A.; Schaper, J.; Mechelke, J.; Coll, C.; Lewandowski, J. Spatial and Temporal Variability in Attenuation of Polar Organic Micropollutants in an Urban Lowland Stream. Environ. Sci. Technol. 2019, 53 (5), 2383-2395.

(59) Benotti, M. J.; Brownawell, B. J. Microbial degradation of pharmaceuticals in estuarine and coastal seawater. Environ. Pollut. 2009, 157 (3), 994-1002.

(60) Conkle, J. L.; Gan, J.; Anderson, M. A. Degradation and sorption of commonly detected PPCPs in wetland sediments under aerobic and anaerobic conditions. J. Soils Sediments 2012, 12 (7), $1164-1173$.

(61) Grossberger, A.; Hadar, Y.; Borch, T.; Chefetz, B. Biodegradability of pharmaceutical compounds in agricultural soils irrigated with treated wastewater. Environ. Pollut. 2014, 185, 168-77.

(62) Loffler, D.; Rombke, J.; Meller, M.; Ternes, T. A. Environmental fate of pharmaceuticals in water/sediment systems. Environ. Sci. Technol. 2005, 39 (14), 5209-18.

(63) Yamamoto, H.; Nakamura, Y.; Moriguchi, S.; Nakamura, Y.; Honda, Y.; Tamura, I.; Hirata, Y.; Hayashi, A.; Sekizawa, J. Persistence and partitioning of eight selected pharmaceuticals in the aquatic environment: laboratory photolysis, biodegradation, and sorption experiments. Water Res. 2009, 43 (2), 351-62.

(64) Tixier, C.; Singer, H. P.; Oellers, S.; Muller, S. R. Occurrence and fate of carbamazepine, clofibric acid, diclofenac, ibuprofen, ketoprofen, and naproxen in surface waters. Environ. Sci. Technol. 2003, 37 (6), 1061-8.

(65) Zou, H.; Radke, M.; Kierkegaard, A.; McLachlan, M. S. Temporal Variation of Chemical Persistence in a Swedish Lake Assessed by Benchmarking. Environ. Sci. Technol. 2015, 49 (16), 9881-8.

(66) Lin, K. D.; Bondarenko, S.; Gan, J. Sorption and persistence of wastewater-borne psychoactive and antilipidemic drugs in soils. J. Soils Sediments 2011, 11 (8), 1363-1372.

(67) Aminot, Y.; Fuster, L.; Pardon, P.; Le Menach, K.; Budzinski, H. Suspended solids moderate the degradation and sorption of waste water-derived pharmaceuticals in estuarine waters. Sci. Total Environ. 2018, 612, 39-48.

(68) Klaminder, J.; Brodin, T.; Sundelin, A.; Anderson, N. J.; Fahlman, J.; Jonsson, M.; Fick, J. Long-Term Persistence of an Anxiolytic Drug (Oxazepam) in a Large Freshwater Lake. Environ. Sci. Technol. 2015, 49 (17), 10406-12.

(69) Rua-Gomez, P. C.; Puttmann, W. Degradation of lidocaine, tramadol, venlafaxine and the metabolites O-desmethyltramadol and O-desmethylvenlafaxine in surface waters. Chemosphere 2013, 90 (6), 1952-9.

(70) Rua-Gomez, P. C.; Puttmann, W. Occurrence and removal of lidocaine, tramadol, venlafaxine, and their metabolites in German wastewater treatment plants. Environ. Sci. Pollut. Res. 2012, 19 (3), 689-99.

(71) Rühmland, S.; Wick, A.; Ternes, T. A.; Barjenbruch, M. Fate of pharmaceuticals in a subsurface flow constructed wetland and two ponds. Ecological Engineering 2015, 80, 125-139.

(72) Rozman, M.; Acuna, V.; Petrovic, M. Effects of chronic pollution and water flow intermittency on stream biofilms biodegradation capacity. Environ. Pollut. 2018, 233, 1131-1137.

(73) Gulde, R.; Anliker, S.; Kohler, H. E.; Fenner, K. Ion Trapping of Amines in Protozoa: A Novel Removal Mechanism for Micropollutants in Activated Sludge. Environ. Sci. Technol. 2018, 52 (1), $52-60$.

(74) Kunkel, U.; Radke, M. Biodegradation of acidic pharmaceuticals in bed sediments: insight from a laboratory experiment. Environ. Sci. Technol. 2008, 42 (19), 7273-9.

(75) Ivshina, I. B.; Tyumina, E. A.; Kuzmina, M. V.; Vikhareva, E. V. Features of diclofenac biodegradation by Rhodococcus ruber IEGM 346. Sci. Rep. 2019, 9 (1), 9159. 
(76) Briones, R. M.; Sarmah, A. K.; Padhye, L. P. A global perspective on the use, occurrence, fate and effects of anti-diabetic drug metformin in natural and engineered ecosystems. Environ. Pollut. 2016, 219, 1007-1020.

(77) Straub, J. O.; Caldwell, D. J.; Davidson, T.; D’Aco, V.; Kappler, K.; Robinson, P. F.; Simon-Hettich, B.; Tell, J. Environmental risk assessment of metformin and its transformation product guanylurea. I. Environmental fate. Chemosphere 2019, 216, 844-854.

(78) Tisler, S.; Zwiener, C. Aerobic and anaerobic formation and biodegradation of guanyl urea and other transformation products of metformin. Water Res. 2019, 149, 130-135.

(79) Poursat, B. A. J.; van Spanning, R. J. M.; Braster, M.; Helmus, R.; de Voogt, P.; Parsons, J. R. Biodegradation of metformin and its transformation product, guanylurea, by natural and exposed microbial communities. Ecotoxicol. Environ. Saf. 2019, 182, 109414.

(80) Baena-Nogueras, R. M.; Gonzalez-Mazo, E.; Lara-Martin, P. A. Degradation kinetics of pharmaceuticals and personal care products in surface waters: photolysis vs biodegradation. Sci. Total Environ. 2017, 590-591, 643-654.

(81) Della Greca, M.; Iesce, M. R.; Previtera, L.; Rubino, M.; Temussi, F. A new photoproduct of the drug furosemide in aqueous media. Environ. Chem. Lett. 2004, 2 (3), 155-158.

(82) Li, M.; Qian, W.-j.; Gao, Y.; Shi, L.; Liu, C. Functional EnzymeBased Approach for Linking Microbial Community Functions with Biogeochemical Process Kinetics. Environ. Sci. Technol. 2017, 51 (20), $11848-11857$.

(83) Blagodatskaya, E.; Kuzyakov, Y. Active microorganisms in soil: Critical review of estimation criteria and approaches. Soil Biol. Biochem. 2013, 67, 192-211.

(84) Schwarzenbach, R. P.; Gschwend, P. M.; Imboden, D. M. Environmental Organic Chemistry, 3rd ed.; John Wiley \& Sons, 2016.

(85) Achermann, S.; Falas, P.; Joss, A.; Mansfeldt, C. B.; Men, Y.; Vogler, B.; Fenner, K. Trends in Micropollutant Biotransformation along a Solids Retention Time Gradient. Environ. Sci. Technol. 2018, 52 (20), 11601-11611.

(86) Mansfeldt, C.; Achermann, S.; Men, Y.; Walser, J.-C.; Villez, K.; Joss, A.; Johnson, D. R.; Fenner, K. Microbial residence time is a controlling parameter of the taxonomic composition and functional profile of microbial communities. ISME J. 2019, 13 (6), 1589-1601.

(87) Johnson, D. R.; Lee, T. K.; Park, J.; Fenner, K.; Helbling, D. E. The functional and taxonomic richness of wastewater treatment plant microbial communities are associated with each other and with ambient nitrogen and carbon availability. Environ. Microbiol. 2015, 17 (12), 4851-60.

(88) Zeglin, L. H. Stream microbial diversity in response to environmental changes: review and synthesis of existing research. Front. Microbiol. 2015, 6, (454). DOI: 10.3389/fmicb.2015.00454

(89) Drury, B.; Rosi-Marshall, E.; Kelly, J. J. Wastewater treatment effluent reduces the abundance and diversity of benthic bacterial communities in urban and suburban rivers. Appl. Environ. Microbiol. 2013, 79 (6), 1897-905.

(90) Wakelin, S. A.; Colloff, M. J.; Kookana, R. S. Effect of wastewater treatment plant effluent on microbial function and community structure in the sediment of a freshwater stream with variable seasonal flow. Appl. Environ. Microbiol. 2008, 74 (9), 265968.

(91) Haritash, A. K.; Kaushik, C. P. Biodegradation aspects of polycyclic aromatic hydrocarbons (PAHs): a review. J. Hazard. Mater. 2009, 169 (1-3), 1-15.

(92) Mandelbaum, R. T.; Allan, D. L.; Wackett, L. P. Isolation and Characterization of a Pseudomonas $\mathrm{Sp}$ That Mineralizes the STriazine Herbicide Atrazine. Appl. Environ. Microbiol. 1995, 61 (4), $1451-1457$.

(93) Li, J.; Luo, C.; Zhang, D.; Song, M.; Cai, X.; Jiang, L.; Zhang, G. Autochthonous Bioaugmentation-Modified Bacterial Diversity of Phenanthrene Degraders in PAH-Contaminated Wastewater as Revealed by DNA-Stable Isotope Probing. Environ. Sci. Technol. 2018, 52 (5), 2934-2944.
(94) Gan, H. M.; Hudson, A. O.; Rahman, A. Y. A.; Chan, K. G.; Savka, M. A. Comparative genomic analysis of six bacteria belonging to the genus Novosphingobium: insights into marine adaptation, cellcell signaling and bioremediation. BMC Genomics 2013, 14 (1), 431.

(95) Ryan, M. P.; Pembroke, J. T.; Adley, C. C. Ralstonia pickettii in environmental biotechnology: potential and applications. J. Appl. Microbiol. 2007, 103 (4), 754-764.

(96) Stamper, D. M.; Radosevich, M.; Hallberg, K. B.; Traina, S. J.; Tuovinen, O. H. Ralstonia basilensis M91-3, a denitrifying soil bacterium capable of using s-triazines as nitrogen sources. Can. J. Microbiol. 2002, 48 (12), 1089-1098.

(97) Nickzad, A.; Mogharei, A.; Monazzami, A.; Jamshidian, H.; Vahabzadeh, F. Biodegradation of Phenol by Ralstonia eutropha in a Kissiris-Immobilized Cell Bioreactor. Water Environ. Res. 2012, 84 (8), 626-634.

(98) Rosenberg, E.; DeLong, E. F.; Lory, S.; Stackebrandt, E.; Thompson, F. The Prokaryotes. 4th ed.; Springer: Berlin, 2014.

(99) Nemergut, D. R.; Schmidt, S. K.; Fukami, T.; O’Neill, S. P.; Bilinski, T. M.; Stanish, L. F.; Knelman, J. E.; Darcy, J. L.; Lynch, R. C.; Wickey, P.; Ferrenberg, S. Patterns and Processes of Microbial Community Assembly. Microbiology and Molecular Biology Reviews 2013, 77 (3), 342-356.

(100) Graham, E. B.; Knelman, J. E.; Schindlbacher, A.; Siciliano, S.; Breulmann, M.; Yannarell, A.; Beman, J. M.; Abell, G.; Philippot, L.; Prosser, J.; Foulquier, A.; Yuste, J. C.; Glanville, H. C.; Jones, D. L.; Angel, R.; Salminen, J.; Newton, R. J.; Bürgmann, H.; Ingram, L. J.; Hamer, U.; Siljanen, H. M. P.; Peltoniemi, K.; Potthast, K.; Bañeras, L.; Hartmann, M.; Banerjee, S.; Yu, R.-Q.; Nogaro, G.; Richter, A.; Koranda, M.; Castle, S. C.; Goberna, M.; Song, B.; Chatterjee, A.; Nunes, O. C.; Lopes, A. R.; Cao, Y.; Kaisermann, A.; Hallin, S.; Strickland, M. S.; Garcia-Pausas, J.; Barba, J.; Kang, H.; Isobe, K.; Papaspyrou, S.; Pastorelli, R.; Lagomarsino, A.; Lindström, E. S.; Basiliko, N.; Nemergut, D. R. Microbes as Engines of Ecosystem Function: When Does Community Structure Enhance Predictions of Ecosystem Processes? Front. Microbiol. 2016, 7, (214). DOI: 10.3389/ fmicb.2016.00214

(101) Bier, R. L.; Bernhardt, E. S.; Boot, C. M.; Graham, E. B.; Hall, E. K.; Lennon, J. T.; Nemergut, D. R.; Osborne, B. B.; Ruiz-González, C.; Schimel, J. P.; Waldrop, M. P.; Wallenstein, M. D. Linking microbial community structure and microbial processes: an empirical and conceptual overview. FEMS Microbiol. Ecol. 2015, 91, (10).fiv113

(102) Krause, S.; Le Roux, X.; Niklaus, P. A.; Van Bodegom, P. M.; Lennon, J. T.; Bertilsson, S.; Grossart, H.-P.; Philippot, L.; Bodelier, P. L. E. Trait-based approaches for understanding microbial biodiversity and ecosystem functioning. Front. Microbiol. 2014, 5, (251). DOI: $10.3389 /$ fmicb.2014.00251 